\title{
In Situ Electrophilic Activation of Hydrogen Peroxide for Catalytic Asymmetric $\alpha$-Hydroxylation of 3-Substituted Oxindoles
}

\author{
Kohsuke Ohmatsu ${ }^{a}$ \\ Yuichiro Ando ${ }^{a}$ \\ Takashi Ooi*a,b \\ ${ }^{a}$ Institute of Transformative Bio-Molecules (WPI-ITbM) \\ and Department of Applied Chemistry, \\ Graduate School of Engineering, Nagoya University, \\ Nagoya 464-8601, Japan \\ tooi@apchem.nagoya-u.ac.jp \\ ${ }^{b}$ CREST, Japan Science and Technology Agency (JST), \\ Nagoya 464-8601, Japan
}

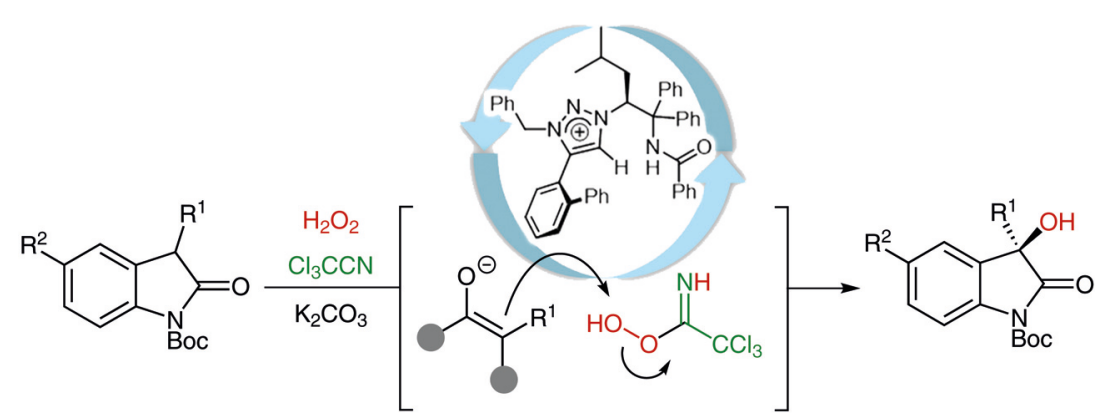

Received: 29.12.2016

Accepted after revision: 06.02.2017

Published online: 27.02 .2017

DOI: 10.1055/s-0036-1558958; Art ID: st-2016-b0882-c

Abstract Peroxy trichloroacetimidic acid, in situ generated from aqueous hydrogen peroxide and trichloroacetonitrile, was found to act as a competent electrophilic oxygenating agent for the direct $\alpha$-hydroxylation of oxindoles. The use of chiral 1,2,3-triazolium salt as a phasetransfer catalyst enabled rigorous absolute stereocontrol in the carbonoxygen bond-forming reaction. The present study provides a new, yet practical method for straightforward access to optically active $\alpha$-hydroxycarbonyl compounds.

Key words hydroxylation, carbonyl compound, hydrogen peroxide, imidic acid, oxindole, chiral ion pair, 1,2,3-triazolium ion

Conversion of the hydroxyl group into a better leaving group, such as acetoxy or sulfonyloxy, represents one of the most fundamental and versatile activation processes for implementing the subsequent bond-forming reactions. Facile generation of trichloroacetimidates from alcohols by the treatment with trichloroacetonitrile is a particularly unique example (Scheme 1 A), ${ }^{1,2}$ which has been classically utilized for glycosylation reactions. ${ }^{3}$ The trichloroacetimidate is a reactive electrophile, yet compatible with Brønsted acid or hydrogen-bond donor catalysis. The groundwork for this hydroxyl-group activation tactic was laid by Payne through the development of the epoxidation of alkenes by peroxy trichloroacetimidic acid, which was generated in situ from hydrogen peroxide and trichloroacetonitrile under basic conditions (Scheme $1 \mathrm{~B}$ ). ${ }^{4,5}$ The potential applicability of this mode of peroxy imidic acid generation to asymmetric catalysis was demonstrated by our group in the development of the enantioselective Payne-type oxidation of $\mathrm{N}$-sulfonyl imines. ${ }^{6}$ On the other hand, we recently established a catalytic system for the direct asymmetric $\alpha$-amination of carbonyl compounds based on the activation of hydroxylamines with trichloroacetonitrile as an electrophilic amine source. ${ }^{7}$ In conjunction with these studies, we became interested in the possibility of exploiting the reactivity of the peroxy imidic acid as an electrophilic oxygenating agent to directly install a hydroxyl group at the $\alpha$-position of carbonyl compounds using hydrogen peroxide as a terminal oxidant (Scheme $1 \mathrm{C}$ ).

A) Activation of alcohols using trichloroacetonitrile

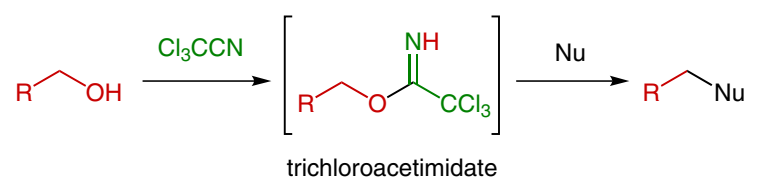

B) Payne-type oxidation

$$
\begin{aligned}
& \mathrm{HO}-\mathrm{OH} \stackrel{\mathrm{Cl}_{3} \mathrm{CCN}}{\longrightarrow}\left[\mathrm{HO}_{\mathrm{O}^{-}} \stackrel{\mathrm{N}_{\mathrm{CCl}_{3}}^{\mathrm{H}}}{\longrightarrow} \stackrel{\mathrm{R}^{1} \aleph_{\mathrm{X}}}{\longrightarrow} \mathrm{R}^{1}<_{\mathrm{X}}^{\mathrm{I}}\right. \\
& \text { peroxy imidic acid } \quad\left(\mathrm{X}=\mathrm{CR}^{2}{ }_{2} \text { or } \mathrm{NR}^{2}\right)
\end{aligned}
$$

C) Asymmetric $\alpha$-hydroxylation of carbonyl compounds

$$
\mathrm{HO}-\mathrm{OH}+\mathrm{R}_{\mathrm{R}^{2}}^{\mathrm{R}_{\mathrm{R}^{3}} \stackrel{\mathrm{Cl}_{3} \mathrm{CCN}}{\longrightarrow}} \stackrel{\mathrm{R}_{\mathrm{R}^{1}}}{\mathrm{O} \mathrm{R}^{2}}
$$

Scheme 1 Transformations based on the activation of hydroxyl group with trichloroacetonitrile

Asymmetric $\alpha$-hydroxylation of carbonyls is an efficient and straightforward method to access chiral tertiary $\alpha$-hydroxycarbonyl compounds, which constitute structural components of many biologically active organic molecules and serve as versatile synthetic intermediates. ${ }^{8}$ There have been various successful examples that relied on the combined use of effective catalysts and appropriate oxygenating 
reagents such as alkyl hydroperoxide, ${ }^{9}$ dimethyldioxirane, ${ }^{10}$ oxaziridine, ${ }^{11}$ nitrosoarene, ${ }^{12}$ and molecular oxygen. ${ }^{13}$ However, reliable catalytic systems that can use abundant and safe-to-handle hydrogen peroxide as an oxidant are extremely scarce because of its low electrophilicity. ${ }^{14}$ Here, as our solution to this problem, we report the development of a highly enantioselective direct $\alpha$-hydroxylation of 3-substituted oxindoles under the catalysis of chiral 1,2,3-triazolium salts. ${ }^{15}$

We initially attempted the reaction of $\mathrm{N}$-Boc-3-phenyloxindole (2a) with excess 30\% aqueous solution of hydrogen peroxide ( 20 equiv) in the presence of trichloroacetonitrile ( 1.0 equiv), potassium carbonate ( 1.0 equiv), and a catalytic quantity of L-alanine-derived chiral 1,2,3-triazolium bromide $1 \mathrm{a} \cdot \mathrm{Br}(5 \mathrm{~mol} \%)$ in toluene at $0{ }^{\circ} \mathrm{C}$ under argon atmosphere (Table 1 , entry 1 ). The carbon-oxygen bond formation proceeded smoothly, and the desired $\alpha$-hydroxyox-

Table 1 Optimization of Reaction Conditions ${ }^{\mathrm{a}}$
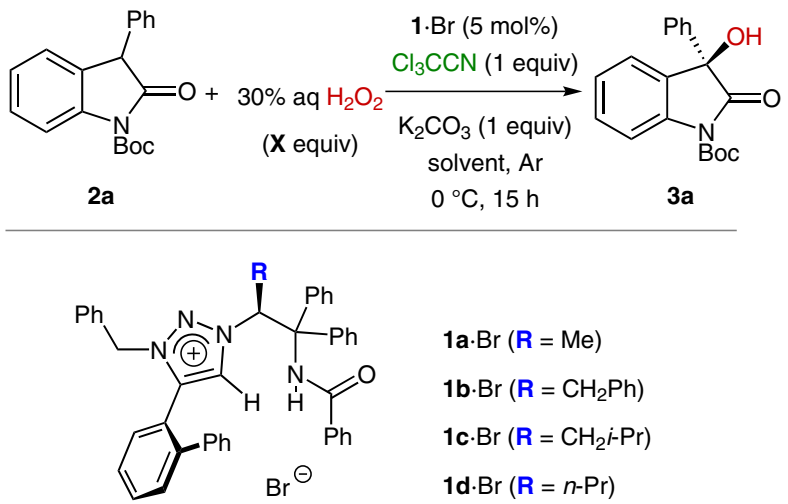

$$
\begin{aligned}
\text { 1a } \cdot \mathrm{Br}(\mathbf{R} & =\mathrm{Me}) \\
\text { 1b. } \mathrm{Br}(\mathbf{R} & \left.=\mathrm{CH}_{2} \mathrm{Ph}\right) \\
\text { 1c } \cdot \mathrm{Br}(\mathbf{R} & \left.=\mathrm{CH}_{2} i-\mathrm{Pr}\right) \\
\text { 1d } \cdot \mathrm{Br}(\mathbf{R} & =n-\mathrm{Pr})
\end{aligned}
$$

\begin{tabular}{clllcl}
\hline Entry & $\mathbf{1}$ & Solvent & $\mathrm{H}_{2} \mathrm{O}_{2}$ (X equiv) & Yield (\%) & ee (\%) \\
\hline 1 & $\mathbf{1 a}$ & toluene & 20 & 65 & 65 \\
$2^{\mathrm{d}}$ & $\mathbf{1 a}$ & toluene & 20 & 0 & - \\
3 & $\mathbf{1 b}$ & toluene & 20 & 77 & 79 \\
4 & $\mathbf{1 c}$ & toluene & 20 & 66 & 83 \\
5 & $\mathbf{1 d}$ & toluene & 20 & 82 & 79 \\
6 & $\mathbf{1 c}$ & $\mathrm{CH}_{2} \mathrm{Cl}_{2}$ & 20 & 49 & 61 \\
7 & $\mathbf{1 c}$ & $\mathrm{Et}_{2} \mathrm{O}$ & 20 & 80 & 90 \\
8 & $\mathbf{1 c}$ & $\mathrm{THF}^{\mathrm{C}}$ & 20 & 10 & 24 \\
9 & $\mathbf{1 c}$ & $\mathrm{EtOAc}^{\mathrm{c}}$ & 20 & 54 & 75 \\
10 & $\mathbf{1 c}$ & $\mathrm{Et}_{2} \mathrm{O}$ & 5 & 83 & 92 \\
11 & $\mathbf{1 c}$ & $\mathrm{Et}_{2} \mathrm{O}$ & 2 & 57 & 92 \\
$12^{\mathrm{e}}$ & $\mathbf{1 c}$ & $\mathrm{Et}_{2} \mathrm{O}$ & 5 & 97 & 94
\end{tabular}

a Unless otherwise noted, reaction was conducted with 2 a $(0.1 \mathrm{mmol}), 30 \%$ aq solution of $\mathrm{H}_{2} \mathrm{O}_{2}, \mathrm{Cl}_{3} \mathrm{CCN}$ (1 equiv), $\mathrm{K}_{2} \mathrm{CO}_{3}$ (1 equiv), and $1 \cdot \mathrm{Br}(5 \mathrm{~mol} \%)$ in solvent $(1 \mathrm{~mL})$ at $0{ }^{\circ} \mathrm{C}$ for $15 \mathrm{~h}$ under $\mathrm{Ar}$.

b Isolated yield.

' Determined by HPLC with chiral column.

d Without $\mathrm{Cl}_{3} \mathrm{CCN}$.

e Reaction was performed at $-10{ }^{\circ} \mathrm{C}$ for $24 \mathrm{~h}$. indole 3a was obtained with moderate enantioselectivity. It should be noted that no oxidation products were detected in the absence of trichloroacetonitrile and substrate $\mathbf{2 a}$ was recovered quantitatively (Table 1 , entry 2 ). This observation emphasizes the critical importance of the combination of hydrogen peroxide and trichloroacetonitrile in promoting direct $\alpha$-hydroxylation. For improving the stereoselectivity, we evaluated the effect of the catalyst structure, specifically that of the aliphatic substituent $(R)$ on the stereogenic center of amino acid origin, and identified the L-leucine-derived triazolium salt $\mathbf{1 c} \cdot \mathrm{Br}$ as an optimal catalyst (Table 1, entry 4). Subsequent screening of the solvents revealed the significant influence on the reactivity and selectivity profiles (Table 1, entries 6-9). In particular, diethyl ether proved to be the solvent of choice, making it feasible to attain high reaction efficiency and enantioselectivity (Table 1 , entry 7). An additional insight gained from a control experiment was that the present hydroxylation could occur in the absence of the triazolium catalyst to give the racemic prod-

Table 2 Scope of Oxindoles ${ }^{\mathrm{a}}$

\begin{tabular}{|c|c|c|c|c|c|}
\hline Entry & $\mathrm{R}^{1}$ & $\mathrm{R}^{2}$ & 3 & Yield $(\%)^{b}$ & ee $(\%)^{c}$ \\
\hline 1 & 4- $\mathrm{MeC}_{6} \mathrm{H}_{4}$ & $\mathrm{H}$ & $3 b$ & 86 & 93 \\
\hline 2 & 4- $\mathrm{MeOC}_{6} \mathrm{H}_{4}$ & $\mathrm{H}$ & $3 c$ & 80 & 92 \\
\hline 3 & 4- $\mathrm{FC}_{6} \mathrm{H}_{4}$ & $\mathrm{H}$ & $3 d$ & 81 & 93 \\
\hline 4 & $3-\mathrm{MeC}_{6} \mathrm{H}_{4}$ & $\mathrm{H}$ & $3 e$ & 89 & 90 \\
\hline 5 & 3- $\mathrm{MeOC}_{6} \mathrm{H}_{4}$ & $\mathrm{H}$ & $3 f$ & 90 & 93 \\
\hline 6 & 1-Naph & $\mathrm{H}$ & $3 g$ & 67 & 92 \\
\hline 7 & 2-Naph & $\mathrm{H}$ & 3h & 93 & 90 \\
\hline 8 & Et & $\mathrm{H}$ & $3 \mathbf{i}$ & 58 & 94 \\
\hline 9 & $n-B u$ & $\mathrm{H}$ & $3 \mathbf{j}$ & 71 & 89 \\
\hline 10 & c- $-\mathrm{HexCH} \mathrm{H}_{2}$ & $\mathrm{H}$ & $3 k$ & 87 & 94 \\
\hline 11 & $\mathrm{CH}_{2}=\mathrm{CHCH}_{2}$ & $\mathrm{H}$ & 31 & 96 & 95 \\
\hline 12 & $B n$ & $\mathrm{H}$ & $3 m$ & 97 & 97 \\
\hline 13 & 4- $\mathrm{MeOC}_{6} \mathrm{H}_{4} \mathrm{CH}_{2}$ & $\mathrm{H}$ & $3 n$ & 96 & 94 \\
\hline 14 & $4-\mathrm{FC}_{6} \mathrm{H}_{4} \mathrm{CH}_{2}$ & $\mathrm{H}$ & 30 & 89 & 98 \\
\hline 15 & $\mathrm{Ph}$ & Me & $3 p$ & 90 & 94 \\
\hline 16 & $\mathrm{Ph}$ & $\mathrm{MeO}$ & $3 q$ & 89 & 94 \\
\hline 17 & $\mathrm{Ph}$ & $\mathrm{F}$ & $3 r$ & 71 & 90 \\
\hline
\end{tabular}

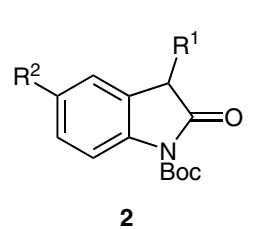

1c. $\operatorname{Br}(5 \mathrm{~mol} \%)$

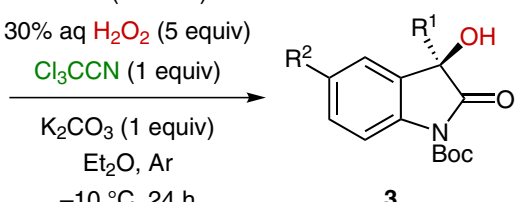

a Reaction was conducted with $2(0.1 \mathrm{mmol}), 30 \%$ aq solution of $\mathrm{H}_{2} \mathrm{O}_{2}$ (5 equiv), $\mathrm{Cl}_{3} \mathrm{CCN}$ (1 equiv), $\mathrm{K}_{2} \mathrm{CO}_{3}$ (1 equiv), and $1 \mathrm{c} \cdot \mathrm{Br}(5 \mathrm{~mol} \%)$ in $\mathrm{Et}_{2} \mathrm{O}(1 \mathrm{~mL})$ at $-10{ }^{\circ} \mathrm{C}$ for $24 \mathrm{~h}$ under $\mathrm{Ar}$.

at $-10{ }^{\circ} \mathrm{C}$ for 24
b Isolated yield.

c Determined by HPLC with chiral column. 
uct (data not shown). We assumed that this competitive background pathway could be suppressed by reducing the amount of hydrogen peroxide. Indeed, the use of five equivalents of hydrogen peroxide enabled higher enantiocontrol without notable rate retardation (Table 1, entry 10). Finally, lowering the temperature to $-10{ }^{\circ} \mathrm{C}$ with prolonged reaction time resulted in an almost quantitative formation of $\mathbf{3 a}$ with a satisfactory level of enantiomeric purity (Table 1, entry 12 ).

The scope of 1c.Br-catalyzed asymmetric direct $\alpha$-hydroxylation of 3-substituted oxindoles 2 was explored under the optimized conditions, and the representative results are summarized in Table $2 .{ }^{16}$ Generally, $5 \mathrm{~mol} \%$ of $\mathbf{1 c} \cdot \mathrm{Br}$ was sufficient to control the hydroxylation of a range of $\mathrm{N}$ Boc oxindoles, giving rise to the corresponding chiral hydroxyoxindoles 3 with uniformly high enantioselectivity. With respect to 3-aryl oxindoles, this protocol tolerated the incorporation of both electron-donating and electron-withdrawing substituents (Table 2, entries $1-5$ ). The reaction with 3-(1-naphthyl)oxindole showed slightly lower conversion (Table 2, entry 6 ), whereas the product was isolated in excellent yield in the oxidation of $\mathbf{2}$ having 2-naphthyl substituent (Table 2, entry 7). 3-Alkyl oxindoles also appeared to be suitable nucleophiles, and a similar degree of reactivity and selectivity was observed (Table 2, entries 8-14). Moreover, this catalytic system well accommodated differently 5 -substituted 3-phenyloxindoles (Table 2 , entries 15 17).

In conclusion, we have developed a catalytic enantioselective $\alpha$-hydroxylation of 3 -substituted oxindoles using aqueous hydrogen peroxide as a terminal oxidant. The judicious use of trichloroacetonitrile and the chiral 1,2,3-triazolium salt for the electrophilic activation of hydrogen peroxide and the stereocontrol of carbon-oxygen bond formation, respectively, allows for the direct asymmetric transfer of hydroxyl group into the $\alpha$-position of carbonyls. We believe that this operationally simple, yet powerful method will be further applied to the development of synthetically valuable asymmetric hydroxylation reactions.

\section{Acknowledgment}

Financial support was provided by CREST (JST), JSPS KAKENHI Grant Number JP16H01015 in Precisely Designed Catalysts with Customized Scaffolding, and the Program for Leading Graduate Schools 'Integrative Graduate Education and Research Program in Green Natural Sciences' at Nagoya University.

\section{Supporting Information}

Supporting information for this article is available online at https://doi.org/10.1055/s-0036-1558958.

\section{References and Notes}

(1) Overman, L. E. Acc. Chem. Res. 1980, 13, 218.

(2) (a) Arnold, J. S.; Zhang, Q.; Nguyen, H. M. Eur. J. Org. Chem. 2014, 4925. (b) Sherif, S. M.; Erian, A. W. Heterocycles 1996, 43, 1083.

(3) (a) Schmidt, R. R.; Michel, J. Angew. Chem., Int. Ed. Engl. 1980, 19, 731. (b) Schmidt, R. R. Angew. Chem., Int. Ed. Engl. 1986, 25, 212.

(4) (a) Payne, G. B.; Deming, P. H.; Williams, P. H.J. Org. Chem. 1961, 26, 659. (b) Payne, G. B. Tetrahedron 1962, 18, 763. (c) Bach, R. D.; Knight, J. W. Org. Synth. 1981, 60, 63. (d) Arias, L. A.; Adkins, S.; Nagel, C. J.; Bach, R. D. J. Org. Chem. 1983, 48, 888.

(5) For Payne-type oxidations of imines: (a) Schirmann, J.-P.; Weiss, F. Tetrahedron Lett. 1972, 13, 633. (b) Kraïem, J.; Kacem, Y.; Khiari, J.; Hassine, B. B. Synth. Commun. 2001, 31, 263. (c) Kraïem, J.; Othman, R. B.; Hassine, B. B. C. R. Chimie 2004, 7, 1119. (d) Tka, N.; Kraïem, J.; Hassine, B. B. Synth. Commun. 2012, $42,2994$.

(6) (a) Uraguchi, D.; Tsutsumi, R.; Ooi, T.J. Am. Chem. Soc. 2013, 135, 8161. (b) Uraguchi, D.; Tsutsumi, R.; Ooi, T. Tetrahedron 2014, 70, 1691. (c) Tsutsumi, R.; Kim, S.; Uraguchi, D.; Ooi, T. Synthesis 2014, 46, 871.

(7) Ohmatsu, K.; Ando, Y.; Nakashima, T.; Ooi, T. Chem 2016, 1, 802.

(8) (a) Matsuda, H.; Yoshida, K.; Miyagawa, K.; Asao, Y.; Takayama, S.; Nakashima, S.; Xu, F.; Yoshikawa, M. Bioorg. Med. Chem. 2007, 15, 1539. (b) Lucas-Lopez, C.; Patterson, S.; Blum, T.; Straight, A. F.; Toth, J.; Slawin, A. M. Z.; Mitchison, T. J.; Sellers, J. R.; Westwood, N. J. Eur. J. Org. Chem. 2005, 1736. (c) Olack, G.; Morrison, H. J. Org. Chem. 1991, 56, 4969.

(9) (a) Acocella, M. R.; Mancheño, O. G.; Bella, M.; Jørgensen, K. A. J. Org. Chem. 2004, 69, 8165. (b) Gong, B.; Meng, Q.; Su, T.; Lian, M.; Wang, Q.; Gao, Z. Synlett 2009, 2659. (c) Lian, M.; Li, Z.; Du, J.; Meng, Q.; Gao, Z. Eur. J. Org. Chem. 2010, 6525. (d) Yao, H.; Lian, M.; Li, Z.; Wang, Y.; Meng, Q. J. Org. Chem. 2012, 77, 9601. (e) Cai, Y.; Lian, M.; Li, Z.; Meng, Q. Tetrahedron 2012, 68, 7973. (f) De Fusco, C.; Meninno, S.; Tedesco, C.; Lattanzi, A. Org. Biomol. Chem. 2013, 11, 896. (g) Wang, Y.; Yin, H.; Qing, H.; Zhao, J.; Wu, Y.; Meng, Q. Adv. Synth. Catal. 2016, 358, 737.

(10) (a) Smith, A. M. R.; Billen, D.; Hii, K. K. Chem. Commun. 2009, 3925. (b) Smith, A. M. R.; Rzepa, H. S.; White, A. J. P.; Billen, D.; Hii, K. K. J. Org. Chem. 2010, 75, 3085.

(11) (a) Toullec, P. Y.; Bonaccorsi, C.; Mezzetti, A.; Togni, A. Proc. Natl. Acad. Sci. U.S.A. 2004, 101, 5810. (b) Ishimaru, T.; Shibata, N.; Nagai, J.; Nakamura, S.; Toru, T.; Kanemasa, S. J. Am. Chem. Soc. 2006, 128, 16488. (c) Jiang, J.-J.; Huang, J.; Wang, D.; Zhao, M.X.; Wang, F.-J.; Shi, M. Tetrahedron: Asymmetry 2010, 21, 794. (d) Zou, L.; Wang, B.; Mu, H.; Zhang, H.; Song, Y.; Qu, J. Org. Lett. 2013, 15, 3106. (e) Gu, X.; Zhang, Y.; Xu, Z.-J.; Che, C.-M. Chem. Commun. 2014, 50, 7870. (f) Naganawa, Y.; Aoyama, T.; Nishiyama, H. Org. Biomol. Chem. 2015, 13, 11499. (g) Lin, X.; Ruan, S.; Yao, Q.; Yin, C.; Lin, L.; Feng, X.; Liu, X. Org. Lett. 2016, $18,3602$.

(12) Lu, M.; Zhu, D.; Lu, Y.; Zeng, X.; Tan, B.; Xu, Z.; Zhong, G. J. Am. Chem. Soc. 2009, 131, 4562.

(13) (a) Masui, M.; Ando, A.; Shioiri, T. Tetrahedron Lett. 1988, 29, 2835. (b) de Vries, E. F. J.; Ploeg, L.; Colao, M.; Brussee, J.; van der Gen, A. Tetrahedron: Asymmetry 1995, 6, 1123. (c) Sano, D.; Nagata, K.; Itoh, T. Org. Lett. 2008, 10, 1593. (d) Yang, Y.; Moinodeen, F.; Chin, W.; Ma, T.; Jiang, Z.; Tan, C.-H. Org. Lett. 2012, 14, 4762. (e) Lian, M.; Li, Z.; Cai, Y.; Meng, Q.; Gao, Z. Chem. Asian J. 2012, 7, 2019. (f) Sim, S.-B. D.; Wang, M.; Zhao, Y. ACS Catal. 2015, 5, 3609. (g) Wang, Y.; Yin, H.; Tang, X.; Wu, Y.; Meng, Q.; Gao, Z. J. Org. Chem. 2016, 81, 7042. 
(14) Li, Z.; Lian, M.; Yang, F.; Meng, Q.; Gao, Z. Eur. J. Org. Chem. 2014, 3491.

(15) Ohmatsu, K.; Kiyokawa, M.; Ooi, T. J. Am. Chem. Soc. 2011, 133, 1307.

(16) In the present system, the $N$-Boc group on the oxindole nitrogen seemed crucial for achieving high efficiency and enantioselectivity. For instance, attempted reaction of $N$-4-methoxyphenyl 3-phenyloxindole under identical conditions described in Table 2 afforded the corresponding $\alpha$-hydroxyoxindole in moderate yield with low enantioselectivity (45\% yield, $28 \%$ ee).

(17) Representative Procedure for Catalytic Asymmetric $\alpha$ Hydroxylation of Oxindoles

A solution of $1 \mathrm{c} \cdot \mathrm{Br}(3.76 \mathrm{mg}, 0.005 \mathrm{mmol})$, oxindole $\mathbf{2 a}(30.9 \mathrm{mg}$, $0.10 \mathrm{mmol})$, and $\mathrm{K}_{2} \mathrm{CO}_{3}(13.8 \mathrm{mg}, 0.10 \mathrm{mmol})$ in $\mathrm{Et}_{2} \mathrm{O}(1.0 \mathrm{~mL})$ was degassed by alternating vacuum evacuation/argon backfill. Then, the resulting mixture was cooled to $-10{ }^{\circ} \mathrm{C}$. To this solution were successively added a $30 \%$ aq solution of $\mathrm{H}_{2} \mathrm{O}_{2}(50 \mu \mathrm{L}$, $0.50 \mathrm{mmol})$ and trichloroacetonitirile $(10 \mu \mathrm{L}, 0.10 \mathrm{mmol})$, and the mixture was stirred for $24 \mathrm{~h}$. The reaction was quenched with a sat. aq solution of $\mathrm{NH}_{4} \mathrm{Cl}$, and the extractive workup was performed with EtOAc. The organic extracts were dried over $\mathrm{Na}_{2} \mathrm{SO}_{4}$, filtered, and concentrated. The crude residue was purified by column chromatography on silica gel (hexane- $\mathrm{CHCl}_{3}=$ 3:1 as eluent) to afford 3a (31.5 mg, $0.097 \mathrm{mmol}, 97 \%$ yield, $94 \%$ ee).

Compound 3a: $[\alpha]_{\mathrm{D}}{ }^{23}=+45.6\left(c=3.0, \mathrm{CHCl}_{3}\right)$ for $94 \%$ ee. ${ }^{1} \mathrm{H}$ NMR $\left(400 \mathrm{MHz}, \mathrm{CDCl}_{3}\right): \delta=7.94(1 \mathrm{H}, \mathrm{d}, J=8.2 \mathrm{~Hz}), 7.40(1 \mathrm{H}, \mathrm{td}, J=$ 8.0, 1.2 Hz), 7.36-7.29 (6 H, m), $7.20(1 \mathrm{H}, \mathrm{t}, J=7.8 \mathrm{~Hz}), 3.42(1$ $\mathrm{H}, \mathrm{s}), 1.63(9 \mathrm{H}, \mathrm{s}) .{ }^{13} \mathrm{C}$ NMR $\left(101 \mathrm{MHz}, \mathrm{CDCl}_{3}\right): \delta=176.0,149.2$, $139.9,139.8,130.3,128.8,128.7,125.7,125.4,125.2,115.6$, $85.0,77.8,28.2$, one peak for aromatic carbon was not found probably due to overlapping. IR (film): 3456, 3001, 2978, 1788, 1609, 1479, 1342, 1285, 1146, 908, $719 \mathrm{~cm}^{-1}$. HRMS $\left(\mathrm{ESI}^{+}\right): \mathrm{m} / \mathrm{z}$ calcd for $\mathrm{C}_{19} \mathrm{H}_{19} \mathrm{NO}_{4} \mathrm{Na}^{+}[\mathrm{M}+\mathrm{Na}]^{+}$: 348.1206; found: 348.1206 . HPLC (ID3, hexane- $i$-PrOH $=10: 1$, flow rate $=0.5 \mathrm{~mL} / \mathrm{min}, \lambda=$ $210 \mathrm{~nm}$ ): $t=15.8 \mathrm{~min}$ (major isomer); $17.5 \mathrm{~min}$ (minor isomer). 